\title{
The erosion of granite surfaces. The Cathedral of Évora as example
}

\author{
D. Costa \\ National Laboratory for Civil Engineering (LNEC), Lisbon, Portugal
}

\begin{abstract}
The evaluation of the erosion in the stone surfaces of a granitic monument highlights the severity of decay due to the presence of salts. The method used and reported here integrates different but relevant information: besides the quantity of material lost by the stone surfaces, their hygroscopic behavior was evaluated in different humidity conditions, complemented by the characterization of the microenvironment where the erosion process takes place. The method used contributes to a better knowledge not only of decay but also of the behavior of these materials over one year, illustrating the dynamism imposed by the presence of salts as the most relevant factor of decay. How to modify the behavior of decayed stone materials is the great challenge of conservation actions.
\end{abstract}

\section{INTRODUCTION}

\subsection{Overview of the subject}

Stone surfaces in historical buildings are usually dynamic and in permanent interaction with the surrounding environment. The impact of climate changes, risk evaluation and the quantification of stone surface recessions on stone buildings have been a main concern and a central topic of several European research projects in this field during the last decade.

From onsite observations or in laboratory/onsite tests, researchers try to quantify stone decay processes on carbonate materials, in order to anticipate the future and to define preventive measures.

However, long-term results on stone decay are not so frequent and usually the information is qualitative rather than quantitative. In fact, the evaluation of damage and the identification of the active processes responsible for decay are particularly important, especially when the final objective is to find adequate solutions for the preservation of surfaces in a specific monument and, for this reason, this matter is also very relevant in conservation.

Visual inspection is widely recognized as the first approach to describe and to evaluate the decay state of surfaces. The use of a common language to describe decay patterns, proposed a long time ago by researchers (Fitzner 1995, 2002) or institutions (ICOMOS 2008), has been increasingly used although not without difficulties and ambiguities. It has been implemented as a good practice, allowing both description and a certain type of quantification, very useful for several relevant purposes required by the best practices in conservation. Besides purposes involving diagnosis or monitoring, it is very useful to report and document the actions taken during the intervention of conservation.

To express weathering and decay in numbers is not an easy task, in particular if we desire to obtain representative data using simple and generally applicable methods. More recently, more or less sophisticated techniques have been proposed to look at the surface and follow the gradual loss of surface using 3D laser scanning and LIDAR systems, but even when it is possible to use 
more complex methods, simple visual examination plays an important role in quantifying decay. Moreover, the use of simple methods is usually the only option available in real practice.

The examination of the surfaces depicts the state of the stone at a particular moment, but it does not capture the rate of decay. For this, a series of inspections is required, usually over a period of several years, and common photographs are used as documents although their objectivity can be questioned.

What methods can be used to evaluate correctly and "easily" the weathering /erosion of the surfaces? The information derived from the academic exercise reported here can be very relevant to decide the most adequate measures to be undertaken during the conservation intervention.

\subsection{The objectives}

This paper presents the guidelines of the work carried out on a granitic monument to evaluate the factors responsible for decay and the methods used to quantify the erosion of surfaces in selected areas of the monument. The work was planned to integrate the preparatory research before the conservation intervention on the Cathedral of Évora (Portugal). Our goal was to understand the influence of the microenvironment on decay patterns observed on the granitic ashlars of the monument.

\section{PLANING THE WORK ON THE MONUMENT}

\subsection{Some relevant aspects of decay observed on the monument}

The construction of the Évora Cathedral dates back to the late twelfth century and lasted for a long period of time, featuring the late Romanesque and Gothic styles. The diversity of materials used to build the monument expresses well the regional variability of the igneous complex from where the construction materials were extracted. For technical and economic reasons, the medieval builders used the upper parts of the rock mass outcrops, where the superficial materials are found naturally altered. As a direct consequence, the blocks present in the cathedral stonework exhibit an inherited alteration that pervades the entire block and examples of extremely poor quality stones may be found. This condition was the first determinant cause of severe degradation forms, namely contour scaling, sand disintegration and back erosion (Delgado \& Costa 2008).

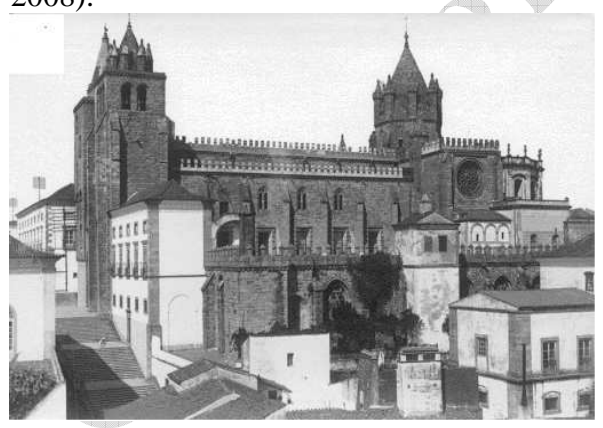

Figure 1. Cathedral of Évora (Portugal) in the 1940s. The lateral façade, one of the towers of the main façade (on the left) and the zimborio (on the right). Reproduction of an old postcard.

\subsection{How serious and how far can the damage reach?}

One of the most significant places in the monument is the lantern tower (zimborio). The interior surface is particularly critical concerning the erosion. The extensive rainwater infiltration is the major source of moisture. Incompatible materials widely used here, particularly cement-based mortars, are also important onsite decay factors. Originally, the masonry was covered by renders and a calcitic mortar was used to mimic the limits of the blocks. Meanwhile, the erosion partially removed the render and the blocks are now uncovered in large areas. Figure 2 illus- 
trates the weathering of the granitic masonry in a place where the stone is now mostly uncovered.

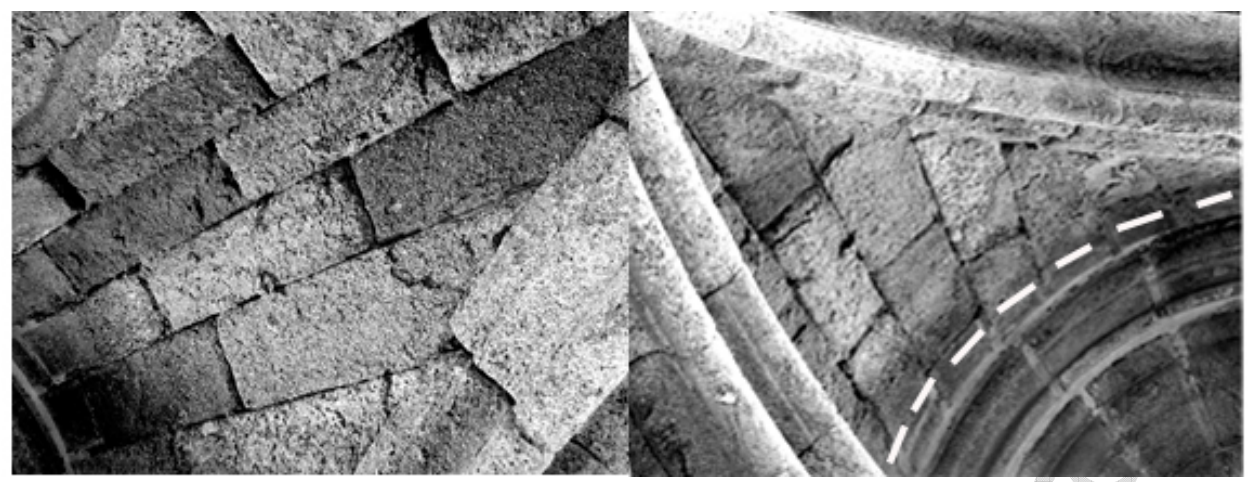

Figure 2. Extensive sand disintegration and erosion in the internal vault. The render is preserved on the right (zone delimited by dashed line).

Sand disintegration justified the installation of a platform under the vault. Afterwards, it was possible to collect the debris detached from the blocks. Since the vault was only accessible to researchers, the spontaneously detached grains could be collected, undisturbed, according to the orientation of the respective sectors and therefore a geographic distribution could be made (see Figure 3).

For about three years it was possible to quantify these materials. The data allows quantifying erosion of the internal surface in this significant space of the monument.

\subsection{Planning the work in the field}

Regarding decay, two general tasks were defined for this particular area:

1) Monitoring of the debris over time;

2) Characterization of the microenvironment (air envelope).

The objectives were to quantify the debris and its salt load content. As a complement, the influence of the microenvironment on the erosion process in progress was also analyzed.

\section{SOME RESULTS}

\subsection{The microenvironment}

The microclimate in Évora is characterized by hot summers and mild winters, but also by great daily variations, particularly in the relative humidity conditions. The indoor climate of the monument is controlled by the external conditions, although characterized by a narrower range of values, especially regarding temperature. Table 1 presents the relevant parameters (expressed in terms of the average values \pm standard deviation and maximum and minimum values) of indoor climate measured in 2000 , taken as example.

Table 1. Indoor climate in the zimbório

\begin{tabular}{|c|c|c|}
\hline & Temperature & Relative Humidity \\
\hline & $\left({ }^{\circ} \mathrm{C}\right)$ & $(\%)$ \\
\hline $\begin{array}{l}\text { January } \\
\text { August }\end{array}$ & $\begin{array}{ll}12.1 \pm 0.6 & (14.1-11.1) \\
26.8 \pm 1.7 & (34.4-24.1)\end{array}$ & $\begin{array}{l}60.6 \pm 3.5 \\
38.9 \pm 7.4\end{array}-\left(\begin{array}{l}(73-50) \\
(54-16)\end{array}\right.$ \\
\hline
\end{tabular}

3.2 The salts as efflorescences

Samples of efflorescences collected in several points of the monument indicate that granitic materials are "contaminated" with complex mixtures of salts. Carbonates, nitrates and sulphates 
are present: i) sodium and magnesium carbonates (Trona, Hidromagnesite and Northupite); ii) magnesium, calcium or sodium sulphates (Epsomite, Gypsum, and Thenardite); iii) sodium and potassium nitrates (Niter and Nitratite). Complex salts like Aftitalite and Humberstonite, composed of sulphate and nitrate anions in several proportions, were also identified. (Costa et al. 2004).

3.3 The debris. How serious is the erosion process inside the lantern tower?

Taking as an example one of the periods monitored (the year 2001), very high material loss were determined in some sectors, reaching $1.5 \mathrm{~g} / \mathrm{m}^{2} /$ day during the summer period. In the areas where the render is still partially preserved ("sec 3", "sec 4", "sec 5" or "sec 6" in Figure 3), the quantity of detached material is lower, around $0.3-0.6 \mathrm{~g} / \mathrm{m}^{2} /$ day. Consistently, the quantity of material detached during the winter is lower than in the summer.

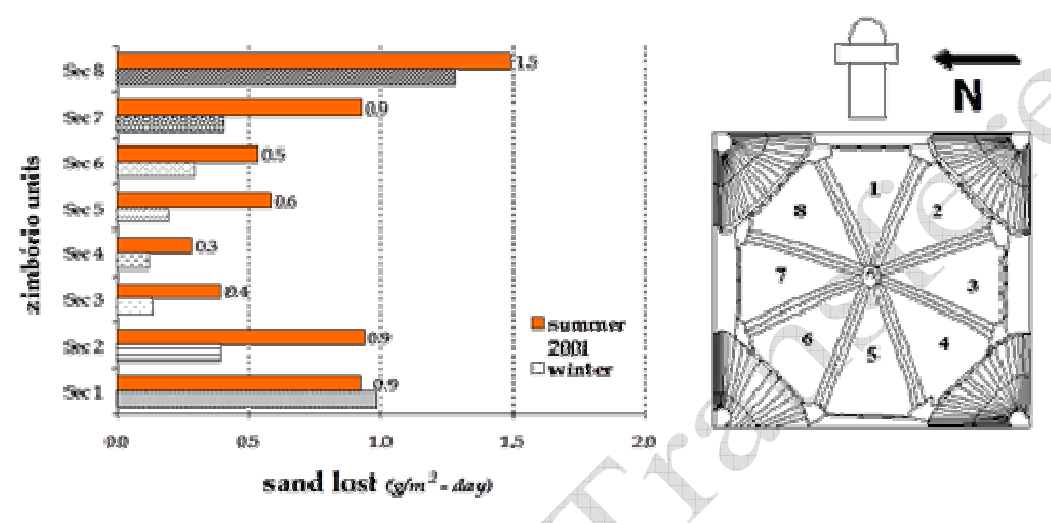

Figure 3. Erosion rates determined for the different sectors of the zimbório internal vault.

3.4 Hygroscopicity of the debris. How serious is the salt load?

Salt minerals present inside the stone are more difficult to analyze and to quantify than efflorescences. The hygroscopic moisture content determination of decayed samples is a very informative technique to quantify the amount of salts, in particular when it can be complemented with Ion Chromatography (IC) (Costa \& Rodrigues 2008). It is worth noting the good correlation of the total salt content determined by IC and hygroscopic moisture content (HMC) values. The granites of ashlars in the zimbório have sulphates and nitrates as suflorescences (see Figure

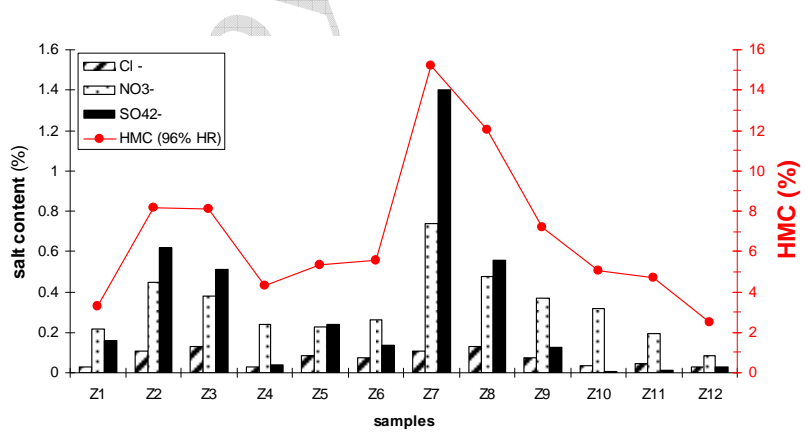

4).

Figure 4. Evaluation of the salt content in decayed granitic samples from the zimbório; hygroscopic moisture content determined at $96 \%$ RH (HMC, line) and soluble salts (anions) determined by IC (bars). 


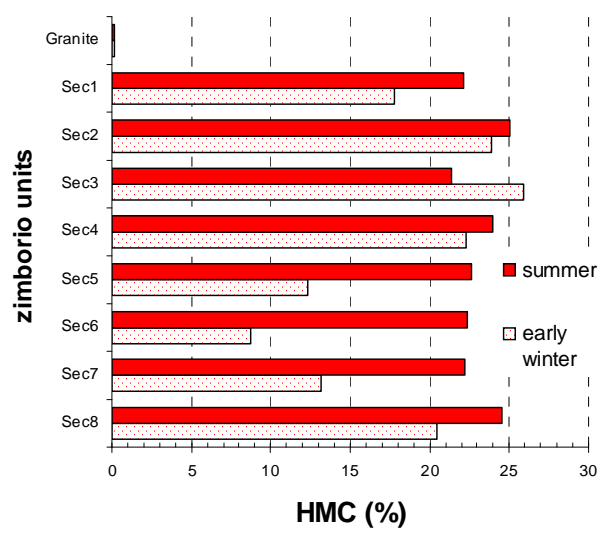

Figure 5. Hygroscopic moisture content (HMC) of debris collected in summer and winter of 2001.

The hygroscopic moisture content of the debris (Figure 5 shows some results) confirms the high amount of hygroscopic salts present as subflorescences (up to 3-4\%, in the summer).

\section{CONCLUSIONS}

Nowadays, granites and similar rocks are considered very durable construction materials. Looking back into the past, several examples show that they can be very fragile, justifying the need for urgent intervention and conservation works. Sand disintegration and scaling are frequent decay patterns on monuments made of granite and similar varieties, with large areas are in risk of loss.

In this research the Cathedral of Évora is presented as case study. This work was planned in the frame of the conservation intervention plan. During the work, it was possible to collect data on the degradation of the materials, in particular in the zimbório area, where this problem is especially relevant.

In this paper some results obtained are presented. The debris detached was collected over years; the material loss allowed evaluating objectively the erosion of the surfaces, which can reach the value of $1.5 \mathrm{~g} / \mathrm{m}^{2} /$ day during the summer period.

The salt load content of these materials and the microenvironment characterization of this space were also relevant to better understanding the erosion process. The materials detached have a strong hygroscopic behavior due to the presence of salts. Complex mixtures, present as efflorescences but mainly as subflorescences, are the major responsible for the fast erosion and for the dynamic of the process in progress.

\section{ACKNOWLEDGEMENTS}

This research was partially funded by IPPAR - Instituto Português do Património Arquitectónico - and by the project PRAXIS, POCTI "Processos de alteração e métodos de conservação do património construído em granito". The authors acknowledge the support of the local IPPAR staff during the research. Special thanks are also due to the team of stone conservation at LNEC; José Delgado Rodrigues, JoãoManuel Mimoso, Luis Nunes and Maria João Revez.

\section{REFERENCES}

Costa, D. \& Delgado Rodrigues, J. 2004. Indoor environment of Évora Cathedral. Internal report 397/04, LNEC, Lisbon. (in Portuguese).

Costa, D., Alves, C. \& Delgado Rodrigues, J. 2004. Study of the salt efflorescences of the Évora Cathedral. Internal report 218/04, LNEC, Lisbon,, 30 pp. (in Portuguese).

Costa, D. \& Delgado Rodrigues, J. 2008. Desalination of granite surfaces with silica sols. In situ evaluation of their efficacy when applied to decayed materials. Proceedings of SWBSS, Copenhagen_, 317327. 
Delgado Rodrigues, J. \& Costa, D. 2007. The conservation of granite in Évora Cathedral. From laboratory to practice. Proceedings of the International Symposium on Stone consolidation in cultural heritage, Lisbon, 101-110.

Fitzner B., Heinrichs K. \& Kownatzki R. 1995. Weathering forms - classification and mapping, Verwitterungsformen - Klassifizierung und Kartierung. Denkmalpflege und Naturwissenschaft, Natursteinkonservierung 1. Ernst \& Sohn, Berlin, p.41-88.

Fitzner B., Heinrichs K. 2002. Damage diagnosis on stone monuments - weathering forms, damage categories and damage indices. In Prikryl, R. \& Viles, H. (ed.): Understanding and managing stone decay, Proceedings of the International Conference "Stone weathering and atmospheric pollution network (SWAPNET)", Charles University, Prague, The Karolinum Press. p.11-56.

ICOMOS-ISCS, 2008. Illustrated glossary on stone deterioration patterns. ICOMOS International Scientific Committee for Stone (ISCS).

Comment [A4]: Reduce the text to fi within the 4 pages limit 